\title{
Description and Executability of a Novel Pre-tied Mini Ligature (Miniloop) in Laparocopic Ovariectomy in Cats
}

\author{
Maria Eduarda Bastos Andrade Moutinho da Conceição', Renata Sitta Gomes Mariano', \\ Roberta Martins Crivelaro', Felipe Faria Pereira da Câmara Barros'², Marco Augusto Machado da Silva³, \\ Paola Castro de Moraes' ${ }^{1}$ Pedro Paulo Maia Teixeira ${ }^{4}$ \& Luis Gustavo Gosuen Gonçalves Dias ${ }^{1}$
}

\begin{abstract}
Background: Ovariectomy $(\mathrm{OVE})$ and ovariohysterectomy $(\mathrm{OVH})$ are the most performed surgical procedures in Veterinary Medicine. In videosurgery, both in stray animals at sterilization campaigns and in the increasing demand of tutors to perform the technique. Laparoscopy results in reduced tissue damage, due to minimal organ manipulation and surgical access hemostasis can be performed by several methods, such as electro-coagulation, clips, and intra and extracorporeal ligatures. A pre-tied ligature system, or endoloop, is a haemostatic technique comprised of a slipknot and knot pusher, which is inserted into the abdominal cavity through one of the laparoscopic ports. The aim of this study was to describe a novel OVE technique in cats, in which haemostasis was performed using miniloop, aimed at reducing the number of ports needed for knot tying.

Material, Methods \& Results: Ten healthy not spayed female cats, aged 6 months to 5 years, were selected for this study. They were submitted to an OVE using miniloop as haemostasis method. Access to the peritoneal cavity was through two $5 \mathrm{~mm}$ ports on the midline of the ventral abdomen, $5 \mathrm{~cm}$ apart, with one immediately caudal to the umbilical scar and the other in between the last pair of teats. The first trocar was inserted at the caudal incision using the Hasson technique and a $5 \mathrm{~mm}$ zero-degree optics attached to a camera was introduced through it. The placement of the second access port was video assisted. For ovary exposure, the patients were positioned in lateral recumbency on the contralateral side to the ovary being removed. The miniloop was composed of a $2 \mathrm{~mm}$ diameter minitrocar, a $1.8 \mathrm{~mm}$ knot pusher, and a pre-tied slipknot. It was introduced percutaneously at the lateral abdominal wall. It was inserted attached to a pre-tied loop ligature. A Babcock forceps was used to guide the slipknot until it enveloped the ovarian vessels and the proximal part of the uterine horn. Subsequently, the knot was tightened with the aid of the knot pusher. A second miniligature was applied. The forceps was removed and a Metzenbaum scissors inserted to cut between the ligatures, releasing the ovary with the nylon ligature but keeping the PDS knot. It was performed at both ovary. Mean $( \pm \mathrm{SD})$ surgical time was 44.8 min $( \pm 13.4)$ and varied significantly $(\mathrm{P}=0.0006)$ between animals, with the shortest time being $29 \mathrm{~min}$ and the longest $66 \mathrm{~min}$. Positioning of the patients in lateral decubitus allowed for good ovarian exposure, without the need for excessive manipulation of the intestinal loops or other abdominal organs. Rupture of the suture thread was the only trans-operative complication observed and occurred in two animals. A second ligature (miniloop) was needed to ensure haemostasis. One cat showed eventration at the site of the caudal port on the second day post-operative.

Discussion: The mean surgical time in the present study was lower than reported by some authors, but longer than anothers. Furthermore, the surgical time from this study is similar to that of other studies in cats in which haemostasis of the OAVC was achieved using bipolar electrocoagulation. Surgical team expertise is of outmost importance in minimizing complications and overcoming problems during videosurgical procedures in order to reduce surgical time, such as gas leakage, extensive incision, and difficulty in manipulating surgical instruments.
\end{abstract}

Keywords: cat, endoloop, spay, videosurgery. 


\section{INTRODUCTION}

Ovariectomy (OVE) and ovariohysterectomy $(\mathrm{OVH})$ are the most performed surgical procedures in Veterinary Medicine, both in stray animals at sterilization campaigns and in the increasing demand of tutors to perform the technique $[1,16]$. Laparoscopy results in reduced tissue damage, due to minimal organ manipulation and surgical access, decreasing trauma and enabling fast and painless recovery [11].

In videosurgery, homeostasis can be performed by several methods, such as electro-coagulation, clips, and intra and extracorporeal ligatures $[12,16]$.

A pre-tied ligature system, or endoloop, is a haemostatic technique comprised of a slipknot and knot pusher, which is inserted into the abdominal cavity through one of the laparoscopic ports [6]. Haemostasis is achieved by pushing and tightening the knot around the desired structure. As well as facilitating the ligature process, by not having to perform it intracorporeally, it has the advantage of not causing thermal damage to adjacent tissues and being of low cost [8].

Based on the advantages of minimally invasive videosurgery, the aim of this study was to describe a novel OVE technique in cats, in which haemostasis was performed using an equipment developed by our research team (miniloop) aimed at reducing the number of ports needed for knot tying.

\section{MATERIALS AND METHODS}

Animals were only included in this study if the owners agreed to the Terms of Free and Informed Consent.

Ten $(n=10)$ female cats were selected for this study based on the following inclusion criteria: age between 6 months and 5 years, healthy, entire, no signs of oestrus, no litter in the last 60 days, and not pregnant. The selected cats were declared fit for the study following clinical and haematological examination (haemogram, and kidney and liver biochemical profiles).

Fasting of solids and liquids were introduced 8 and $2 \mathrm{~h}$ prior to surgery, respectively. At the preoperative period, the animals were weighed using a digital scale and trichotomy was performed on the ventral, right, and left lateral abdominal region, from the xiphoid area to the pubis. Immediately prior to anaesthesia, the bladder of all cats was emptied manually so as to reduce the risk of iatrogenic lesion of this organ.
Prophylactic antimicrobial therapy with benzathine benzylpenicillin $\left(\text { Bepeben }^{\circledR}\right)^{1}$ [40000 UI/kg] was administered intramuscularly and anti-inflammatory meloxicam (Maxican $\left.0.2 \%{ }^{\circledR}\right)^{2}[0.2 \mathrm{mg} / \mathrm{kg}]$ given subcutaneously prior to anaesthesia induction.

Pre-anaesthetic medication combined intramuscular chlorpromazine $\left(\text { Clorpromaz }^{\circledR}\right)^{3}[0.05$ $\mathrm{mg} / \mathrm{kg}]$ and methadone $\left(\text { Mytedom }^{\circledR}\right)^{4}[0.3 \mathrm{mg} / \mathrm{kg}]$. After $15 \mathrm{~min}$, anaesthesia was induced with propofol (Provive $\left.1 \%{ }^{\circledR}\right)^{5}[4 \mathrm{mg} / \mathrm{kg}]$ given intravenously. Animals were intubated with an endotracheal tube and anaesthesia maintained with $0.5 \%$ isofluorane (Isoflurano $\left.{ }^{\circledR}\right)^{6}$ vaporized in $100 \%$ oxygen in a semiclosed circuit.

Access to the peritoneal cavity was through two $5 \mathrm{~mm}$ ports on the midline of the ventral abdomen, 5 $\mathrm{cm}$ apart, with one immediately caudal to the umbilical scar and the other in between the last pair of teats.

The first trocar was insertedat the caudal incision using the Hasson technique and a $5 \mathrm{~mm}$ zerodegree optics attached to a camera was introduced through it. The abdominal cavity was inspected and pneumoperitoneum established using a $\mathrm{CO}_{2}$ automatic insufflator 7 at $2 \mathrm{~L} / \mathrm{min}$. Intra-abdominal pressure was maintained between 4 and $5 \mathrm{mmHg}$.

The placement of the second access port was videoassisted by $180^{\circ}$ rotation of the trocar attached to the shutter. For ovary exposure, the patients were positioned in lateral recumbency on the contralateral side to the ovary being removed.

The miniloop equipment was composed of a $2 \mathrm{~mm}$ diameter minitrocar of percutaneous access (Figure1 A), a $1.8 \mathrm{~mm}$ knot pusher (Figure 1 B), and a pre-tied slipknot [2]. The knot pusher was placed inside the minitrocarso as to enable the slipknot to be pushed inside the abdominal cavity (Figure $1 \mathrm{C}$ ).

The miniloop was introduced percutaneously at the lateral abdominal wall, approximately $3 \mathrm{~cm}$ caudal to the last rib, at the level of the costochondral articulation, as close as possible to the ovary, and in triangulation with the two ports. It was inserted attached to a pre-tied loop ligature using 2-0 PDS thread.

Through the cranial port, a Babcock atraumatic forceps ( $5 \mathrm{~mm} \times 42 \mathrm{~cm}$ )was introduced and, concomitantly, the slipknot of the miniloop was pushed through prior to ovary apprehension (Figure 2A). The Babcock forceps was used to guide the slipknot until it enveloped the ovarian arteriovenous complex (OAVC) and 
the proximal part of the uterine horn. Subsequently, the knot was tightened with the aid of the knot pusher (Figure $2 \mathrm{~B}$ ).

A second mini ligature using 2-0 nylon was applied in the same fashion round the OAVC but closer to the ovary, which was left suspended by the ligature thread (Figure $2 \mathrm{C}$ ). The forceps was removed and a Metzenbaum scissors inserted to cut between the ligatures (Figure 2 D), releasing the ovary with the nylon ligature but keeping the PDS knot for haemostasis of the OAVC. The scissors were removed from the port and the Babcock forceps re-introduced to aid in the removal of the ovary through the trocar. The same procedure was performed on the left ovary, following repositioning of the patient.

Once both ovaries had been removed, the abdominal cavity was re-inspected for potential haemorrhages, $\mathrm{CO}_{2}$ pressure reduced, and the pneumoperitoneum drained. Trocar removal was followed by muscle and skin suture with 3-0 nylon and Sultan and Wolf patterns, respectively.

The surgical time, from the time of skin incision to the tying of the last skin knot,was recorded in all animals.

It was made descriptive statistical for the surgical time, and complications.
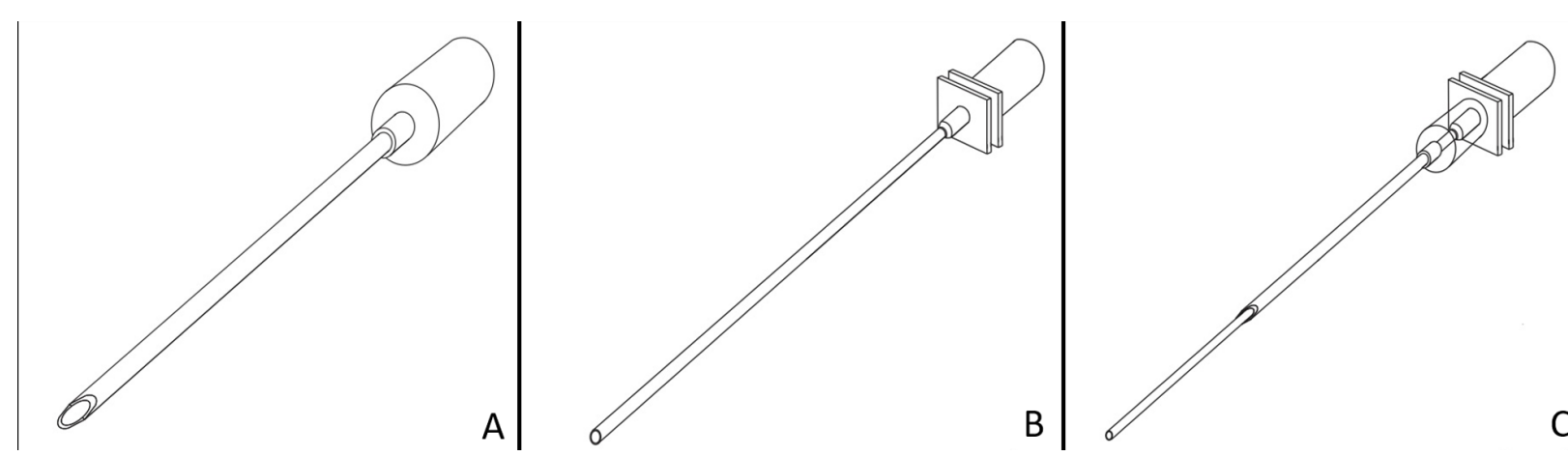

Figure 1. Schematic drawing of the pre-tied mini ligature equipment (miniloop). Composed of cannulated access needle ( $2 \mathrm{~mm}$ minitrocar) with sharp bevel tip for percutaneous access (A); and knot pusher with lightly filed straight tip to avoid damage to the suture thread (B). This instrument $(1.8 \mathrm{~mm}$ ) closes the loop once the knot is pushed, enabling occlusion of blood vessels (B). Final setting, with the knot pusher inside the miniport (C), note that the former must be longer than the later and narrow enough to fit inside it. [FCAV-Unesp Jaboticabal].

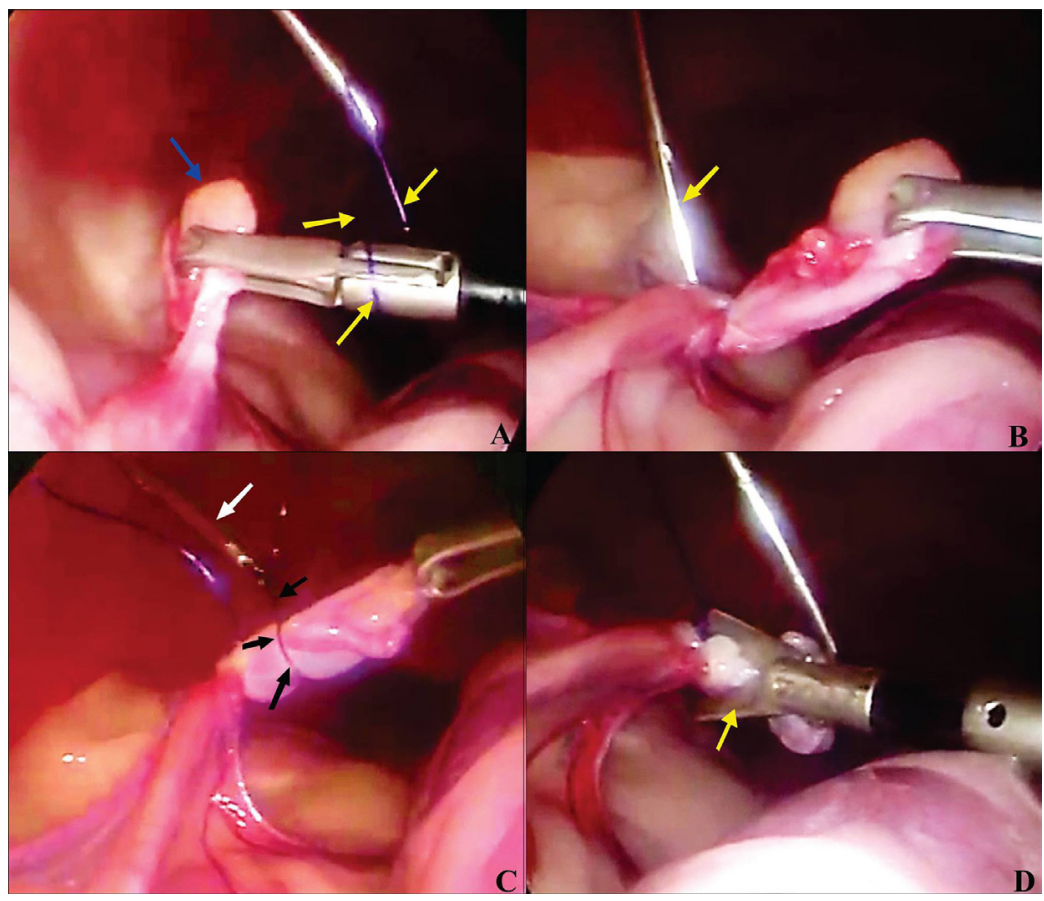

Figure 2. Photographic images of videosurgical haemostasis/ligature of the ovarian arteriovenous complex (OAVC) with pre-tied mini ligature (miniloop). A- ovary apprehension (blue arrow) with Babcock forceps after passing through the polydioxanone (PDS) thread loop (yellow arrows), introduced through the minitrocar with bevel tip (white arrow). B- tying of the PDS loop proximal to the ovarian pedicle with the aid of the knot pusher (yellow arrow). Cinsertion of the second miniloop (white arrow) with nylon thread (black arrows), which is tied as close as possible to the ovary. D- Metzenbaum scissors (yellow arrow) for sectioning of the ovarian pedicle between the two ligatures. The nylon ligature is released and removed from the abdominal cavity through the access port together with the ovary. 


\section{RESULTS}

Mean ( \pm SD) weight of patients was $2.29 \mathrm{~kg}$ \pm 0.74 (1.7 to $3.8 \mathrm{~kg})$. All animals were docile and adapted to the recovery environment in which they were kept. Within $1 \mathrm{~h}$ of surgery, food and water had been ingested by all cats.

Mean $( \pm$ SD) surgical time was $44.8 \mathrm{~min}( \pm$ 13.4) and varied significantly $(P=0.0006)$ between animals, with the shortest time being $29 \mathrm{~min}$ and the longest $66 \mathrm{~min}$.

Intraperitoneal $\mathrm{CO}_{2}$ pressure of $4-5 \mathrm{mmHg}$ enabled good visualization of the abdominal organs and provided sufficient room inside the abdominal cavity for the manipulation of surgical instruments. Positioning of the patients in lateral decubitus allowed for good ovarian exposure, without the need for excessive manipulation of the intestinal loops or other abdominal organs. The location of the two ports on the linea alba enabled triangulation with the miniloop, which was inserted laterally and close to the ovaries, facilitating manipulation and avoiding clashing of the surgical instruments and the camera, even in smaller animals.

The method of introduction of the first trocar by mini-laparotomy proved to be safe, without any case of perforation or laceration of abdominal organs; however, in some animals the incision made was bigger than the trocar and thus had to be reduced with nylon sutures to prevent $\mathrm{CO}_{2}$ leakage.

Rupture of the suture thread was the only transoperative complication observed and occurred in two animals. A second ligature (miniloop) was needed to ensure haemostasis in only one of the animals, as there was no haemorrhage on the other. There was no need for open surgery in any of the cases.

One cat showed eventration at the site of the caudal port on the second day post-operative due to rupture of the nylon suture thread of the abdomen and a second surgical intervention was needed to correct it.

\section{DISCUSSION}

Positioning of patients in dorsal decubitus with lateralization, without Trendelenburg, enabled excellent visualization of the ovaries and minimal manipulation of the organs; similarly to some authors [5,7], but contrary to anothers [18], who used 10 degrees inclination without lateralization. However, it was observed in the present study that the Trendelenburg position does not aid ovarian exposure in cats due to their very cranial location in this species and, consequently, the intestinal loops would still compromise visualization.

Although pneumoperitoneum pressure of 10 $\mathrm{mmHg}$ has been previously recommended [12,17], the $4 \mathrm{mmHg}$ pressure used in this study enabled excellent visualization and manipulation of the organs, similarly to previous reports $[5,7,18]$. It is known that the greater the intra-abdominal pressure, the greater the $\mathrm{CO}_{2}$ absorption by the peritoneum and, consequently, the greater the cardiorespiratory alterations observed [13]. Thus, the minimal pressure required for good organ visualization should be preconized.

Although in a study in bitches [10], and in one with cats [12], reported greater surgical time for haemostasis using suture thread than bipolar electrocoagulation or clips, the mean surgical time in the present study was lower than those reported by these authors. Furthermore, the surgical time from this study is similar to that of other studies in cats in which haemostasis of the OAVC was achieved using bipolar electrocoagulation $[5,17,18]$.

Some studies reported mean surgical time of 22 and $25 \mathrm{~min}$ [4,7], which is lower than the present study. However, the surgeons in those studies had extensive experience in performing laparoscopic surgery, suggesting that the expertise of the surgical team could have greater influence on surgical time than the type of haemostasis employed. Thus, the use of theminiloop does not increase the difficulty or length of the surgery.

Laparoscopic OVH and OVE through a single access point (LESS) or total-NOTES, which employ a single trocar and optics with working channel, do not allow for haemostasis using suture thread, as only one surgical instrument can be used at a time. Therefore, support sutures are necessary to enable haemostasis by clips, clamps, or electrocoagulation $[14,15]$. The haemostasis technique used in this study would enable the above surgery to be performed, as only one surgical instrument needs to be used at a time; however, this could not be tested due to the lack of access to optics with working channel.

Some of the complications reported in the trans-operative period of laparoscopic OVH and OVE are haemorrhage, organ lacerations by the trocar, subcutaneous emphysema, and the need to convert to open surgery. At the post-operative period, the complications often observed are haematomas, discharge at the site of skin suture, infection, suture dehiscence, and incisional 
hernia $[3,5,17]$. In the present study, complications were observed in only one animal (incisional hernia).

A simple way of avoiding organ laceration by trocar insertion is by doing so in an open manner, through miniceliotomy [7], as performed in the present study. The use of this procedure may be the main reason for the lack of organ laceration observed in the present study; however, manual emptying of the bladder prior to trocar insertion also minimized the chances of laceration, as the organ was not at the site of port introduction.

Haemorrhage of the ovarian pedicle and uterine blood vessels are very common complications during the trans-operative period [17]. Only in one female there was minimal haemorrhage after sectioning of the OAVC suture thread; however, there was no need for intervention and no post-operative complications were present.

Surgical team expertise is of outmost importance in minimizing complications and overcoming problems during videosurgical procedures in order to reduce surgical time, such as gas leakage, extensive incision, and difficulty in manipulating surgical instruments $[7,9,17]$. This affirmation corroborates the present study, in which the complications were minimal and the surgical time reduced significantly with the repetitions.

\section{CONCLUSION}

The technique proposed in this study, with the equipment developed by our surgical team, is executable, simple, and resulted in minimal complications. The equipment is easy to manipulate and can be successfully used in feline OVE. Furthermore, it is easy to acquire and of low cost.

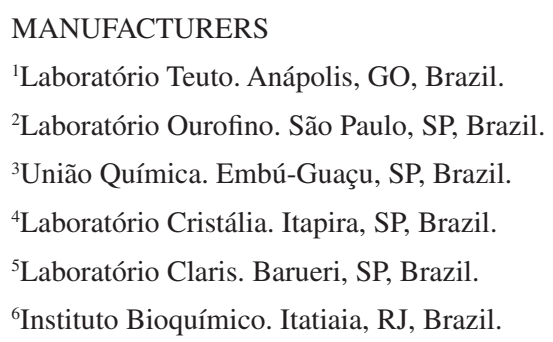

Ethical approval. This study was approved by the Ethics Committee in the Use of Animals (CEUA, protocol 011090/15) of the School of Agrarian Sciences and Veterinary Medicine (FCVA) of the UNESP - Universidade Estadual Paulista, Campus Jaboticabal - SP, Brazil.

Declaration of interest. The authors report no conflicts of interest. The authors alone are responsible for the content and writing of the paper.

\section{REFERENCES}

1 Atallah F.A., Silva R.S., Ramos M.L.M., Oliveira A.L.A., França T.N. \& Brito M.F. 2013. Complicações póscirúrgicas em cadelas submetidas a ovário-histerectomia no Rio de Janeiro. Revista Brasileira de Medicina Veterinária. 35(1): 61-69.

2 Brun M.V. 2015. Hemostasia. In: Brun M.V. (Ed). Videocirurgia em pequenos animais. Rio de Janeiro: Roca, pp.128149.

3 Culp W.T., Mayhew P.D. \& Brown D.C. 2009. The effect of laparoscopic versus open ovariectomy on postsurgical activity in small dogs. Veterinary Surgery. 38: 811-817.

4 Ferreira G.S., Franco C.A.D., Santos C.L., Atallah F.A., Estupnan O.F.T., Silva S.J.Q. \& Oliveira A.L.A. 2013. Ovariectomia laparoscópica em cadela e gatas. Revista Brasileira de Medicina Veterinária. 35(1): 55-60.

5 Gauthier O., Holopherne-Doran D., Gendarme T., Chebroux A., Thorin C., Tainturier D. \& Bencharif D. 2015. Assessment of Postoperative Pain in Cats After Ovariectomy by Laparoscopy, Median Celiotomy, or Flank Laparotomy. Veterinary Surgery. 44: O23-O30.

6 Katsinelos P., Kountouras J., Paroutoglou G., Beltsis A., Chatzimavroudis G., Zavos C., Vasiliadis I., Katsinelos T. \& Papaziogas B. 2006. Endoloop-assisted polypectomy for large pedunculated colorectal polyps. Surgery and Endoscopy. 20(8): 1257-1261.

7 Kim Y.K., Lee S.J., Park S.J., Lee S.S., Lee H.J. \& Yeon S.C. 2011. Feasibility of single-portal access laparoscopic ovariectomy in 17 cats. Veterinary Record. 169(7): 179.

8 Lim Y.H., Ng S.P., Mg P.H., Tam A.E. \& Jamil M.A. 2007. Laparoscopic salpingectomy in tubal pregnancy: prospective randomized trial using endoloop versus electrocautery. Journal of Obstetrics and Gynaecology Research. 33(6): 855-862. 
9 Malm C., Savassi-Rocha P.R., Gheller V.A., Oliveira H.P., Lamounier A.R. \& Foltyneck V. 2004. Ovário-histerectomia: estudo experimental comparativo entre as abordagens laparoscópica e aberta na espécie canina: intra-operatório - I. Arquivo Brasileiro de Medicina Veterinária e Zootecnia. 56(4): 457-466.

10 Mayhew P.D. \& Brown D.C. 2007. Comparison of three techniques for ovarian pedicle hemostasis during lapaoscopicassisted ovariohysterectomy. Veterinary Surgery. 36: 541-547.

11 Robertson E., Webb C. \& Twedt D. 2014. Diagnóstic laparoscopy in the cat. Journal of Feline Medicine and Surgery. 16: $18-26$.

12 Schiochet F., Beck C.A.C., Silva A.P.F.F., Contesini E.A., Alievi M.M., Stedile R., Pinto V., Jurinitz D.F. \& Pellizari M. 2009. Ovário-histerectomia laparoscópica em felinos hígidos: estudo comparativo de três métodos de hemostasia. Arquivo Brasileiro de Medicina Veterinária e Zootecnia. 61(2): 369-377.

13 Shih A.C., Case J.B., Coisman J.G., Nisaza N.M., Amora Junior D. \& Maisenbacher III H.W. 2015. Cardiopulmonary Effects of Laparoscopic Ovariectomy of Variable Duration in Cats. Veterinary Surgery. 44: O2-O6.

14 Silva M.A.M., Toniollo G.H., Flores F.N., Valadão C.A.A., Medeiros R.M., Cardilli D.J., Gering A.P., Teixeira P.P.M., Serafini G.M.C., Coutinho Junior A.S., Libardoni R.N. \& Brun M.V. 2015. Surgical time and complications of total transvaginal (total-NOTES), single-port laparoscopic-assisted and conventional ovariohysterectomy in bitches. Arquivo Brasileiro de Medicina Veterinária e Zootecnia. 67(3): 647-654.

15 Silva M.A.M. \& Teixeira P.P.M. 2015. Cirurgia laparoscópica por único acesso (LESS) nomenclatura princípios básicos. In: Brun M.V. (Ed). Videocirurgia em pequenos animais. Rio de Janeiro: Roca, pp.308-314.

16 Silveira C.P.B., Machado E.A.A., Silva W.M., Marinho T.C.M.S., Ferreira A.R.A., Burger C.P. \& Costa Neto J.M. 2013. Estudo retrospectivo de ovariossalpingo-histerectomia em cadelas e gatas atendidas em Hospital Veterinário Escola no período de um ano. Arquivo Brasileiro de Medicina Veterinária e Zootecnia. 65(2): 335-340.

17 Tavares D.C., Souza F.F., Quarterone C., Rodrigues V., Pereira L.F., Brun M.V. \& Toniollo G.H. 2016. Videoassisted ovariohysterectomy in domestic cats (Felis catus, Linnaeus, 1758) using two access portals. Acta Cirúrgica Brasileira. 31(2): 84-91.

18 Van Nimwegen S.A. \& Kirpenstejin J. 2007. Laparoscopic ovariectomy in cats: comparison of laser and bipolar eletrocoagulation. Journal of Feline Medicine and Surgery. 9: 397-403. 